\title{
SISTEM INFORMASI PUBLIKASI YAYASAN RAUDHATUL MADINAH SAWAHLUNTO DENGAN MENGGUNAKAN BAHASA PEMROGRAMAN PHP DESAIN WEBSITE
}

\author{
Nanda Jarti \\ Program Studi Teknik Informatika Universitas Putera Batam
}

\begin{abstract}
The purpose of the research in Yayasan Raudhatul Madinah Sawah Lunto is to give the information about the development of the Yayasan Raudhatul Madiah Sawah Lunto to the society. After doing the reseacrh, the researcher found that Yayasan Raudhatul Madiah had a problem in using technology in promotion. To promote. Eventhough they had used computer for collecting data, saving data, and the others, however it was not maximal. Thus it probably make some errors in data processing. At the research, I'm as The Author did Field Research to obtain primary data to design a new system. After the studied, The Author conclude that in implementing computerized systems in this case, The PHP Program Language and MySQL Database is the appropriate applications, because these applications is very easy in the academic process that usually involves a lot of user.
\end{abstract}

Keywords: information sistem, php, database, website

\section{PENDAHULUAN}

Yayasan Raudhatul Madinah perlu melakukan pengembangan sistem. Karena Yayasan ini belum menggunakan teknologi informasi dalam melakukan promosi. Adapun yang perlu dikembangkan adalah sistem publikasi Yayasan yang lebih maju, dimana promosi Yayasan hanya di lakukan dengan cara manual dengan menyebarkan brosur - brosur sehingga menyebabkan terbatasnya ruang promosi Yayasan. Serta informasi yang didapat Yayasan umumnya memakan waktu yang relatif lama.

Dengan menggunakan Bahasa Pemograman PHP Desaign Website dapat memberikan kemudahan dalam melakukan promosi yayasan. Dimana Yayasan Raudhatul Madinah mampu mengembangkan sitem promosi yang baik yang dapat di akses oleh masyarakat serta Yayasan lain guna saling menukar informasi dalam bidang yang sama terutama Pendidikan Usia Dini.

Berdasarkan permasalahan itu penulis melakukan analisis dan pengembangan sistem informasi dengan menggunakan Bahasa Pemograman PHP desaign website untuk memperbaharui sistem promosi Yayasan Raudhatul Madinah yang terletk dikota sawahlunto. Pengembangan ini meningkatkan mutu dari pelayanan yang akan diberikan pada masyarakat dengan menghasilkan sistem yang lebih baik dan maju. Adapun judul yang penulis angkat 
adalah "SISTEM INFORMASI PUBLIKASI YAYASAN RAUDHATUL MADINAH SAWAHLUNTO DENGAN MENGGUNAKAN BAHASA PEMOGRAMAN PHP DESAIN WEBSITE"

\section{Perumusan Masalah}

1. Apakah dengan menerapkan Bahasa Pemograman PHP membantu Yayasan dalam perluasan ruang promosi?

2. Apakah dengan menerapkan Bahasa Pemograman PHP mempercepat proses penyampaian informasi mengenai Yayasan?

3. Apakah dengan penggunaan sistem komputer pada Yayasan akan menghasilkan kinerja yang optimal.

\section{Hipotesa}

Berdasarkan rumusan masalah yang telah di ungkapkan diatas, maka penulis dapat mengemukakan hipotesa sebagai berikut:

1. Dengan menerapkan aplikasi PHP Desaign Website pada Yasasan Raudhatul Madinah Sawahlunto, maka ruang promosi Yayasan lebih luas, mempercepat transformasi dengan menggunakan ICT dan Yayasan dapat bertukar informasi dengan Yayasan lain dalam ruang lingkup yang sama.

2. Dengan menerapkan Bahasa Pemograman PHP akan mempercepat proses penyampaian informasi mengenai Yayasan.

3. Dengan menggunakan sistem komputer pada Yayasan akan menghasilkan kinerja yang optimal.

\section{Tinjauan dan Manfaat Penelitian}

\section{Tujuan Penelitian}

Adapun tujuan penulisan skripsi ini adalah:

1. Merancang sebuah website untuk memperluas informasi tentang Yasasan Raudhatul Madinah Sawahlunto agar memudahkan guru dan orang tua siswa dalam mendapatkan informasi dengan menerapkan aplikasi PHP Desaign Website .

2. Memudahkan pihak Yayasan dalam menyebarkan luaskan pengumuman tentang perkembangan Yayasan atau informasi-informasi penting kepada pihak luar.

3. Memberikan layanan yang memuaskan kepada pihak luar yang membutuhkan informasi-informasi penting tentang Yayasan untuk mengesnal Yayasan lebih jauh lagi.

\section{Manfaat Penelitian}

Adapun manfaat dari penulisan skripsi ini adalah:

1. Sebagai wadah yang cepat dan mudah dalam memberikan informasi yang penting kepada pihak dalam dan luar dari Yayasan. 
2. Sebagai pedoman bagi pihak lain yang memerlukan dalam hal pemberian informasi yang cepat dan mudah.

\section{Ruang Lingkup Masalah}

Agar pembahasan yang dilakukan lebih terarah dan sesuai dengan tujuan yang ingin dicapai, maka perlu adanya sesuatu batasan masalah :

1. Penerapan aplikasi PHP Desaign Website pada Yasasan Raudhatul Madinah Sawahlunto

2. Informasi-informasi yang akan disampaikan melalui website ini hanya berhubungan dengan kepentingan promosi Yayasan serta informasi penting lainnya.

\section{Metode Penelitian}

Metode penelitian yang diterapkan dalam pengumpulan data adalah :

1. Penelitian Lapangan (Field Research) Melakukan penelitian langsung ke objek penelitian untuk mengambil data yang dibutuhkan dengan menggunakan daftar pertanyaan dan wawancara.

2. Penelitian Perpustakaan (Library Research)

Membaca dan mempelajari buku-buku yang berhubungan dengan masalah yang dibahas

3. Penelitian Laboratorium (Laboratory Research)

Penelitian pada laboratorium komputer dengan menerapkan langsung aplikasi $\mathrm{PhP}$ Desaign Website pada Yasasan Raudhatul Madinah Sawahlunto, sehingga sistem yang dibuat benar-benar dapat membantu.

Adapun spesifikasi perangkat keras dan lunak yang digunakan adalah:

A. Perangkat keras (Hardware)

1. Processor Intel Pentium Dual-Core Inside

2. RAM kapasits 2 GB jenis DDR merk MCPRO

3. Harddisk kapasitas 80 GB merk Toshiba

4. Monitor digital 15 inchi merk Toshiba

5. DVD-RW

6. Printer HP F 2476

B. Perangkat lunak (Software)

1. Sistem Operasi Microsoft Windows XP Profesional

2. Microsoft Office XP

3. Softwre PHP Triad

4. Serta software pendukung lainnya

\section{Tinjauan Umum Yayasan}

\section{Sejarah Berdirinya Yayasan}

Sekilas tentang Kota Sawahlunto yang memiliki visi kota wisata tambang yang berbudaya. Memiliki wilayah $\pm 27.344 .7 \mathrm{Ha}$,dan jumlah penduduk 53.686 jiwa(data 
statistik Tahun 2007). Terdiri dari 4 kecamatan yaitu kecamatan silungkang,kecamatan lembah sugar, Kecamatan Barangin, dan Kecamatan Talawi dan 10 kelurahan 27 desa.

Pemerintahan Kota Sawahlunto melalui dinas pendidikan sangat peduli terhadap pendidikan anak usia dini(PAUD), melalui perpanjangan tangannya FORUM PAUD dan HIMPAUDI tumbuh dengan baik fasilitas PAUD diantaranya 59 buah pos PAUD, 15 buah kober play group dan 2 buah kober/play group yang langsung melayani penitipan anak,serta taman penitipan anak 1 buah,jumlah kelurahan 78 buah wadah yang mengayomi tingkat pendidikan dasar anak ini tersebar sampai ke pelosok desa dan Kelurahan yang ada (47 buah).

Play Group dan Taman Penitipan Anak Raudhatul Madinah yang berdiri dan dirintis pada tanggal 10 Mei 2005, berkat kerja keras pengelola dan pendidikdan tidak terlepas dari fasilitas dan pembinaan yang diberikan oleh Pemda Kota Sawahlunto melalui Dinas Kota Sawahlunto Play Group dan Taman Penitipan Anak Raudhatul Madinah tumbuh dan berkembang dengan baik.

Play Group dan Taman Penitipan Anak Raudhatul Madinah bertempat di Kelurahan Durian, Kecamatan Barangin Kota Sawahlunto, letak geografisnya Play Group dan Taman Penitipan Anak ini berada $\pm 5 \mathrm{~km}$ dari pusat kota, berada di tengah-tengah diantara 4 Kecamatan yang ada di Kota Sawahlunto, sehingga jangkauan untuk seluruh sasaran amat strategis.

Play Group dan Taman Penitipan Anak Raudhatul Madinah bertujuan untuk ikut serta mencerdaskan generasi penerus bangsa, agar terwujud anak-anak yng cerdas, berkualitas dan mandiri, serta bertaqwa kepada Allah SWT.

\section{LANDASAN TEORI}

\section{Tujuan Perancangan Sistem}

Tahap rancangan sistem mempunyai tujuan utama yaitu :

1. Untuk memenuhi kebutuhan pemakai sistem.

2. Untuk memberikan gambaran yang jelas dan rancang bangun yang lengkap pada Pemrograman komputer dan ahli-ahli teknik yang lainnya yang terlihat.

Kedua tujuan tahap rancangan sistem tersebut lebih cenderung pada rancangan sistem yang terinci yaitu pembuatan rancang bangun yang jelas dan lengkap yang nantinya digunakan untuk mencapai tujuan analisis sistem.

\section{Tahapan Perancangan Sistem}

1. Mendefinisikan masalah, yaitu menentukan hal-hal apa saja sebenarnya yang menjadi masalah dalam perusahaan sehingga kita dapat menetukan pemecahan yang sesuai.

2. Analisis masalah, yaitu meneliti dengan sebaik mungkin masalah yang sudah ditentukan dan memikirkan alternatif yang terbaik dalam pemecahan terhadap perancangan sistem yang baru saja digambarkan.

3. Perancangan global, yaitu melakukan perancangan global terhadap sistem yang baru dengan menggunakan metode-metode perancangan secara garis besar. 
4. Perancangan detail, yaitu dengan menentukan bentuk-bentuk perancangan secara terperinci, dengan menggunakan metode-metode perancangan yang sering digunakan apakah itu desain output, desain input, desain file, dan struktur program.

5. Program, yaitu membuat rancangan sistem yang baru dengan menggunakan bahasa pemrograman tertentu sesuai dengan aplikasi yang dibutuhkan.

6. Testing, yaitu mengandalkan pengujian terhadap sistem program yang dirancang sesuai dengan keinginan yang dikehendaki dalam perancangan sebelumnya.

7. Implementasi, yaitu menetapkan program yang telah dibuat kedalam sistem untuk menggunakan program tersebut, apakah sesuai dengan yang diinginkan.

8. Evaluasi, operasi, dan perawatan, yaitu melakukan operasi terhadap program dan juga melakukan penawaran secara umum untuk memelihara program yang ada.

9. Dokumentasi, yaitu melakukan penduplikasian data melalui program yang dibuat sehingga apabila sewaktu-waktu terjadi hal-hal yang tidak diinginkan maka kita dapat mengantisipasinya.

Sedangkan definisi dari kata informasi yaitu sebagai berikut:

Informasi adalah data yang diolah menjadi bentuk jamak dari bentuk lebih berguna dan lebih berarti bagi yang menerimanya ( Jogiyanto HM, 2001:8)

Kwalitas dari suatu informasi tergantung pada tiga hal yaitu:

1. Akurat

Informasi yang dihasilkan harus bebas dari kesalahan-kesalahan. Akurat juga berarti informasi harus jelas mencerminkan maksudnya.

2. Tepat pada waktunya

Informasi tepat waktu, karena informasi merupakan landasan di dalam pengambilan keputusan di tingkat manajemen yang lebih tinggi.

3. Relevan

Informasi tersebut mempunyai manfaat untuk pemakainya, Relevansi informasi untuk setiap pemakai yang satu dengan yang lainnya berbeda.

\section{Pengertian Sistem Informasi}

Dari pembahasan di atas telah diketahui bahwa informasi merupakan hal yang sangat penting bagi perusahaan dalam pengambilan keputusan. Adapun pengertian sistem informasi menurut Robert. A. Leitch dan K. Roscoe Davis sebagai berikut :

"Sistem informasi adalah suatu sistem di dalam suatu organisasi yang mempertemukan kebutuhan pengolahan transaksi harian, mendukung operasi, bersifat manajerial dan kegiatan strategi dari suatu organisasi dan menyediakan pihak luar tertentu dengan laporan-laporan yang diperlukan" ( Jogiyanto HM, 2001: 11 ).

\section{Manfaat Sistem Informasi}


Sistem informasi dikembangkan dan dibangun karena memiliki manfaat yang besar bagi komponen sistem di dalam suatu manajemen organisasi atau perusahaan. Manfaat yang didapat dari sistem informasi dapat di klasifikasi sebagai berikut:

1. Manfaat mengurangi biaya

2. Manfaat mengurangi kesalahan-kesalahan

3. Meningkatkan kecepatan aktifitas

4. Meningkatkan perencanaan dan pengendalian manajemen

Manfaat sistem informasi dalam bentuk keuntungan berwujud (tangible benefis) dan tidak berwujud (intangible benefis) yaitu :

Keuntungan berwujud antara lain :

1. Pengurangan-pengurangan biaya operasi

2. Pengurangan kesalahan-kesalahan telekomunikasi

Keuntungan tidak bewrujud antara lain :

1. Peningkatan pelayanan lebih baik

2. Peningkatan kepuasan kerja personil

3. Peningkatan pengambilan keputusan

\section{Daur Hidup Pengembangan Sistem}

Siklus hidup sistem informasi dimulai dari perencanaan, pengembangan (survei, analisa, desain, pembuatan, implementasi, pemeliharaan), dan dievaluasi secara terusmenerus untuk menetapkan apakah sistem informasi tersebut masih layak diaplikasikan, jika tidak, sistem informasi tersebut akan diganti dengan yang baru dan dimulai dari perencanaan kembali.Siklus Daur Hidup Pengembangan Sistem dapat kita lihat pada gambar 2.1 berikut:

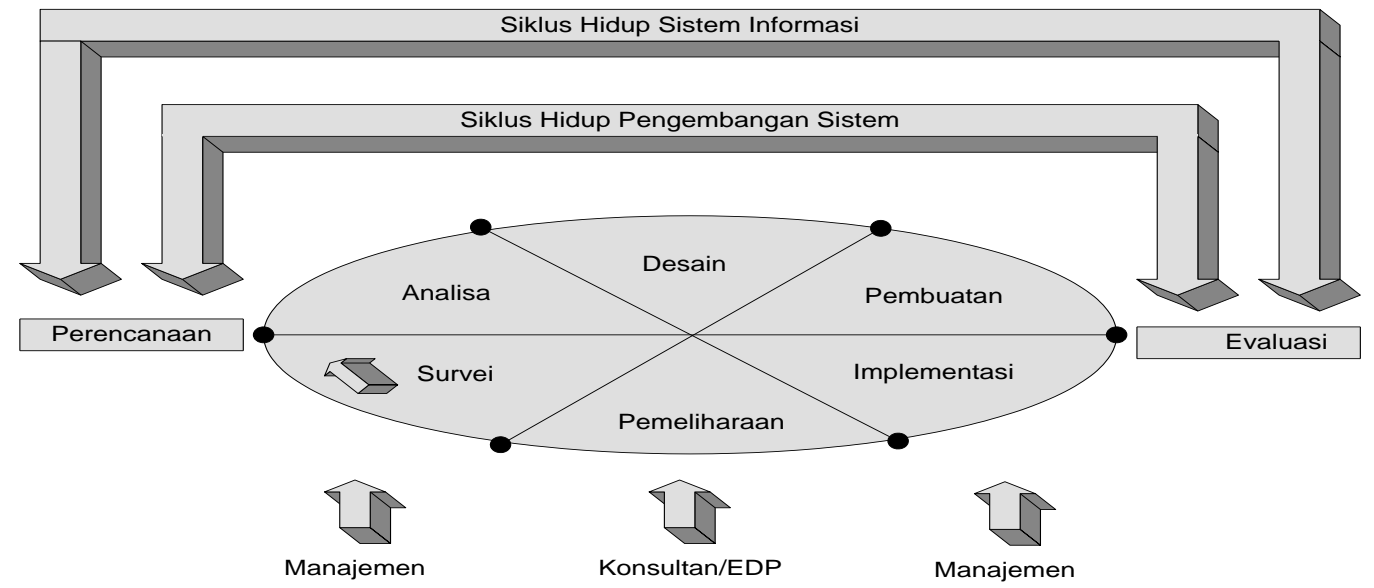

Gambar Daur Hidup Pengembangan Sistem 
Dari gambar 2.1 dapat dilihat bahwa tahap perencanaan dan tahap evaluasi merupakan kegiatan/tugas dari user dan manajemen, sedangkan tahap pengembangan merupakan tugas bagian EDP/Konsultan.

Tahapan utama pengembangan sistam informasi

a. Survei, bertujuan untuk mengetahui ruang lingkup pekerjaan

b. Analisis, bertujuan untuk memahami sistem yang ada, mengidentifikasi masalah dan mencari solusinya.

c. Desain, bertujuan untuk mendesain sistem baru yang dapat menyelesaikan masalahmasalah yang dihadapi.

d. Pembuatan, membuat sistem baru (hardware, software).

e. Implementasi, bertujuan untuk mengimplementasikan sistem yang baru.

f. Pemeliharaan, bertujuan agar sistem dapat berjalan secara optimal.

\section{Database}

Kita asumsikan sebuah lemari arsip dan kita bertugas untuk mengelolanya, hal yang kita lakukan adalah menerapkan suatu aturan atau cara tertentu bagaimana keseluruhan arsip tadi dapat ditempatkan atau disusun. Tindakan paling sederhana yang dilakukan adalah menyusun/menempatkan arsip-arsip tadi sesuai kedatangannya(kronologisnya) da tanpa pengelompokan.

\section{Pengertian Database}

Basis Data dapat didefenisikan dari beberapa sudut pandang:

a. "Himpunan kelompok data (arsip) yang saling berhubungan yang diorganisasikan sedemikian rupa agar kelak dapat dimanfaatkan kembali dengan cepat dan mudah"(Fathansyah,Ir.1999).

b. "Kumpulan data yang saling berhubungan yang disimpan secara bersama sedemikian rupa dan tanpa pengulangan (redudansi) yang tidadk perlu, untuk memenuhi berbagai kebutuhan (Fathansyah,Ir.1999).

c. "Kumpulan file/ tabel/ arsip yang saling berhubungan yang disimpan dalam media penyimpanan" (Fathansyah,Ir.1999).

Adapun prinsip kerja dari basis data mempunyai banyak kesamaan dengan lemari arsip yaitu kenudahan, dan kecepatan dalam pengambilan kembali data/ arsip. Bedanya hanya terletak pada media penyimpanannya. Kalau lemari arsip disimpan dalam lemari besi atau kayu yang langsung dikelola oleh tangan manusia sedangkan basis data menggunakan media penyimpanan elektronik seperti disket atau hardisk Perbedaan ini dapat dilihat gambar 2.2
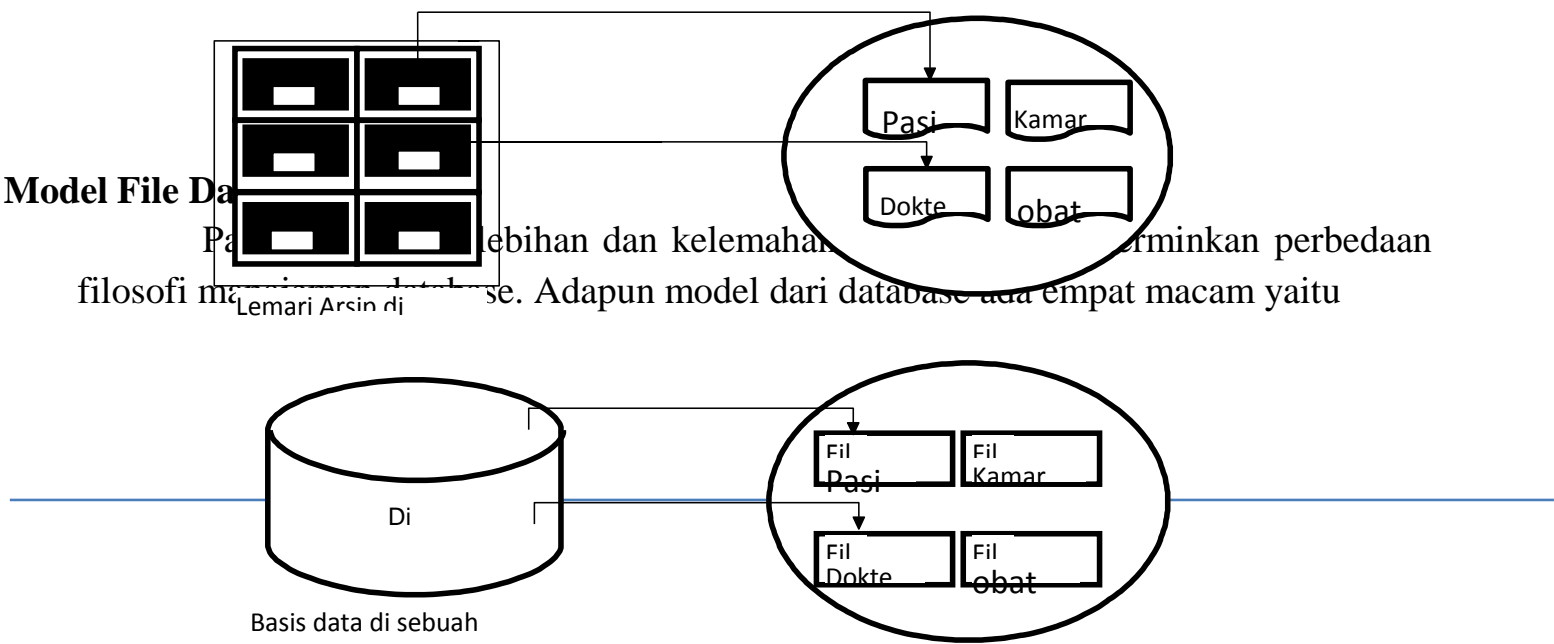
1. Model Hirarki

Model ini sering dikenal dengan binary tree atau binary relationship. Struktur tree ini menunjukkan hubungan antara data membentuk seperti pohon. Suatu pohon dibentuk dari beberapa elemen grou data yang berjenjang, disebut dengan node. Node yang paling atas disebut akar root. Tiap dapat bercabang ke node yang lainnya. Data yang diwakili dengan struktur pohon ini harus memenuhi dua kondisi yaitu:

a. Pohon yang mempunyai sebuah root saja

b. Tiap-tiap node kecuali root hanya dapat mempunyai sebuah orang tua(parent ) saja, tapi tiap-tiap node boleh mempunyai beberapa anak(child).

2. Model Network

Struktur data jaringan (Network data structure) disebut juga dengan plox data structure. Pada structure jaringan ini, tiap-tiap node mempunyai lebih dari satu orang tua

\section{Model Relational}

Model ini dikembangkan berdasarkan konsep matematika dari hubungan dan kumpulan entity atau beberapa objek dari kumpulan atribut-atributnya. Model relational ini mempunyai beberapa karakteristik:

a. File dalam bentuk tabel yang persis dengan file urut.

b. Hubungan antar record didasarkan daripada nilai field kunci.

Maksud utama dari model database relational ini adalah meletakkan semua hubungan data dalam tabel dua dimensi. Data dalam model ini dapat didefenisikan dalam hubungan nyata terhadap item data yang ada dalam record.

\section{Model Objek}

Pada program berorientasi objek diperkenalkan adanya objek dalam program. Objek menjadi komponen utama dalam program berorientasi objek. Dalam sebuah program menu, tampilan layar, tulisan yang tertera di layar, isian tempat user memasukkan data adalah sebuah objek. Penerapankonsep objek ini membuat penulisan lebih sederhana, kompak, fleksibel dan dengan kemampuan yang jauh lebih baik.

\section{Sekilas Mengenai MySQL}

MySQL adalah Relational Database Management Sistem (RDBMS) yang didistribusika secara gratis di bawah licensi GPL (GeneralPublic License). Dimana setiap orang bebas untuk menggunakan MySQL, namun tidak boleh dijadikan produk turunan yang bersifat close source atau komersial.

MySQL sebenarnya merupakan turunan salah satu konsep utama dalam database sejak lama yaitu, SQL (Structured Query Language). SQL adalah sebuah konsep pengoperasian database, terutam untuk pemilihan/seleksi dan pemasukan data, 
yang memungkinkan pengoperasian data dikerjakan dengan mudah secara otomatis. Keandalan suatu sistem database (DBMS) dapat diketahui dari cara kerja optimizer-nya dalam melakukan proses perintah perintah SQL, yang dibuat oleh user maupun program program aplikasinya. Sebagai databse server, MySQL dapat dikatakan lebih unggul dibandingkan database server lainnya dalam query data. Hal ini terbukti untuk query yang dilakukan oleh single user, kecepatan query MySQL bisa sepuluh kali lebih cepat dari PostgreSQL dan lima kali lebih cepat dibandingkan Interbase. Kemmpuan yang cukup menakjubkan untuk sebuah software gratisan.

MySQL adalah satu dari sekian banyak sitem database, merupakan terobosan solusi yang tepat dalam aplikasi database. Didukung oleh ribuan bahkan jutaan komunitas pengguna di internet yang siap membantu. Selain itu juga tersedia mailing list dan homepage khusus yang memberikan tutorial serta dokumen lengkap.

\section{ANALISA DAN HASIL}

\section{ANALISA DAN PERANCANGAN}

\section{Analisa Sistem Yang Sedang Berjalan}

Adapun proses penyajian informasi saat ini masih berjalan secara manual, yaitu dengan menginformasikan melalui penyebaran brosur-brosur, spanduk atau melalui radio. Beberapa permasalahan yang sering timbul dalam penyebaran informasi seperti yang telah diterangkan pada latar belakang masalah pada BAB I.

Dengan melakukan penelitian dan pengamatan terhadap permasalahan yang ada, sebaiknya pihak Yayasan Raudhatul Madinah perlu hendaknya mengembangkan suatu system informasi untuk mempromosikan dan mempublikasikan informasi tentang Yayasan Raudhatul Madinah yang dapat diakses secara online, dimanapun dan kapanpun oleh setiap user membutuhkan informasi, dengan adanya system seperti itu tentunya pelayanan terhadap user akan leboh baik lagi.

\section{Disain Sistem Baru}

Tahap awal rancangan system baru ini bertujuan untuk menanggulangi masalah dan kendala yang selama ini dihadapi oleh pihak Yayasan Raudhatul Madinah dalam penyajian informasi kepada masyarakat yang membutuhkan informasi khusus bagi para orang tua. Tahap perancangan yang harus dilakukan adalah menganalisa masalah-masalah yang ada, yang akan menjadi landasan bagi penulis untuk mendapatkan masukan, bagaimana bentuk output, file-file apa saja yang dibutuhkan, menyusun menu pogram dan bentuk program agar sesuai dengan kebutuhan dan tujuan yang diinginkan. 


\section{PENGUJIAN SISTEM}

\section{Pengujian Sistem}

Pengujian sistem dilakukan agar mengetahui sejauh mana program bebas dari kesalahan, sebelum program diterapkan. Akan tetapi untuk menjalankan program ini, terlebih dahulu harus dilakukan beberapa pengaturan pada sistem program komputer, seperti terlihat pada gambar 4.1 berikut ini:

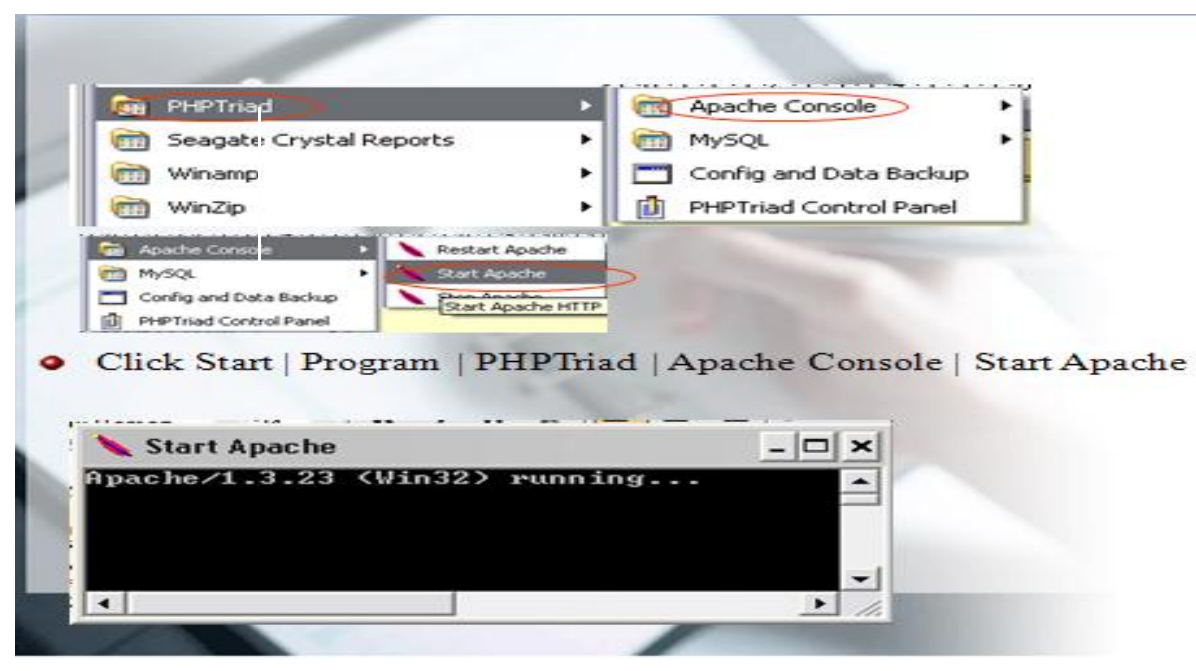

Gambar koneksi PHP Triad

\section{Hasil Pengujian Program}

Setelah pengujian program selesai dilakukan maka akan didapat hasil dari pengujian tersebut. Adapun hasil dari pengujian adalah sebagai berikut .

\section{Halaman Web Awal}

Halaman Web Awal pada sistem ini merupakan Halaman Web yang akan ditampilkan, Halaman Web ini bisa diakses oleh semua orang. Tampilan Halaman Web awal dapat dilihat pada gambar 4.3 di bawah ini : 


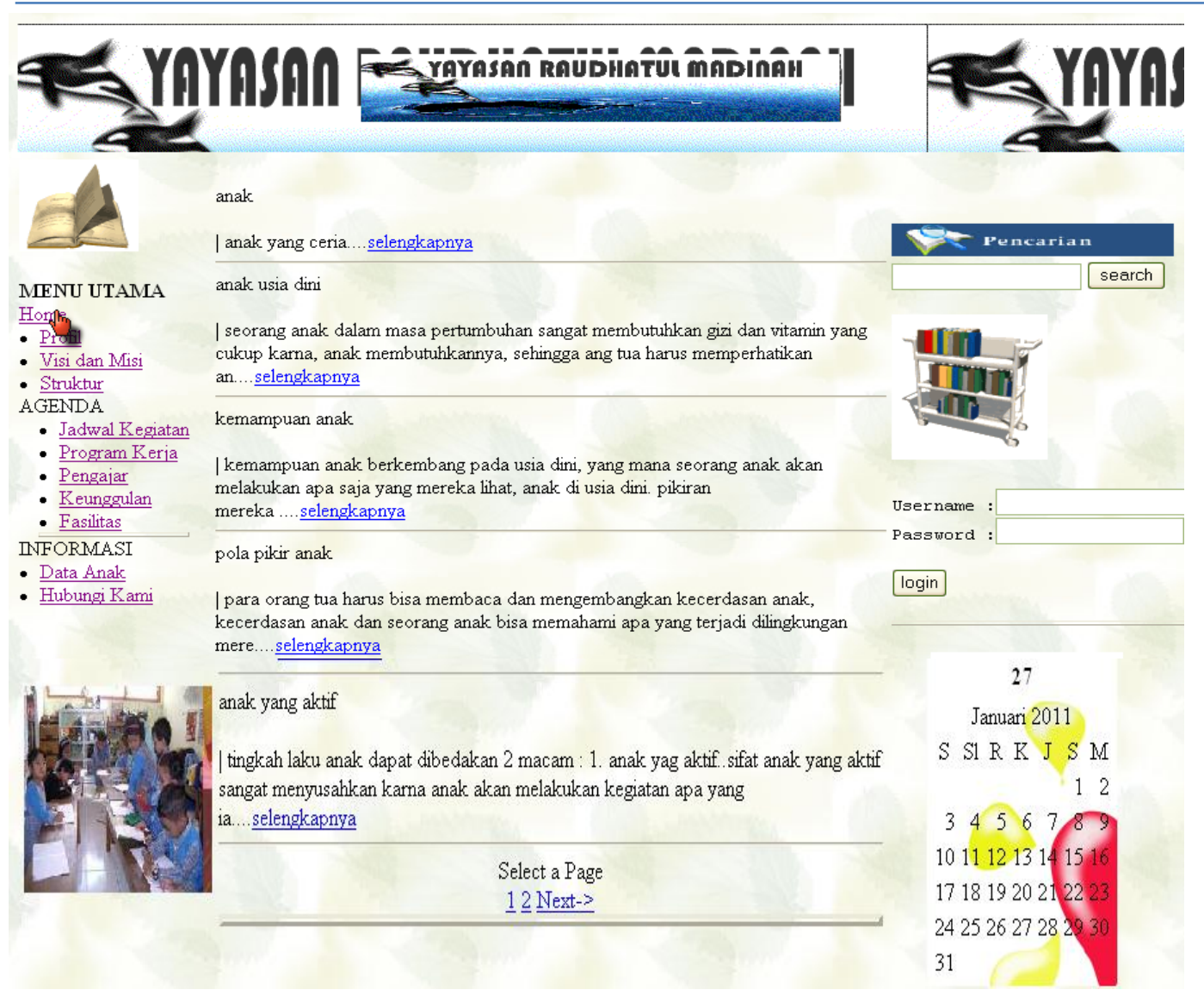

\section{Gambar Halaman Web Profil}

Halaman ini menampilkan seluruh informasi dan berita yang dapat diakses, halaman ini terdapat beberapa pilihan yang dapat dilihat informasinya yang berkaitan dengan yayasan raudhatul madinah, diantaranya, Home, Profil, Visi dan Misi, dan Daftar Karyawan.

\section{Halaman Web Profil}




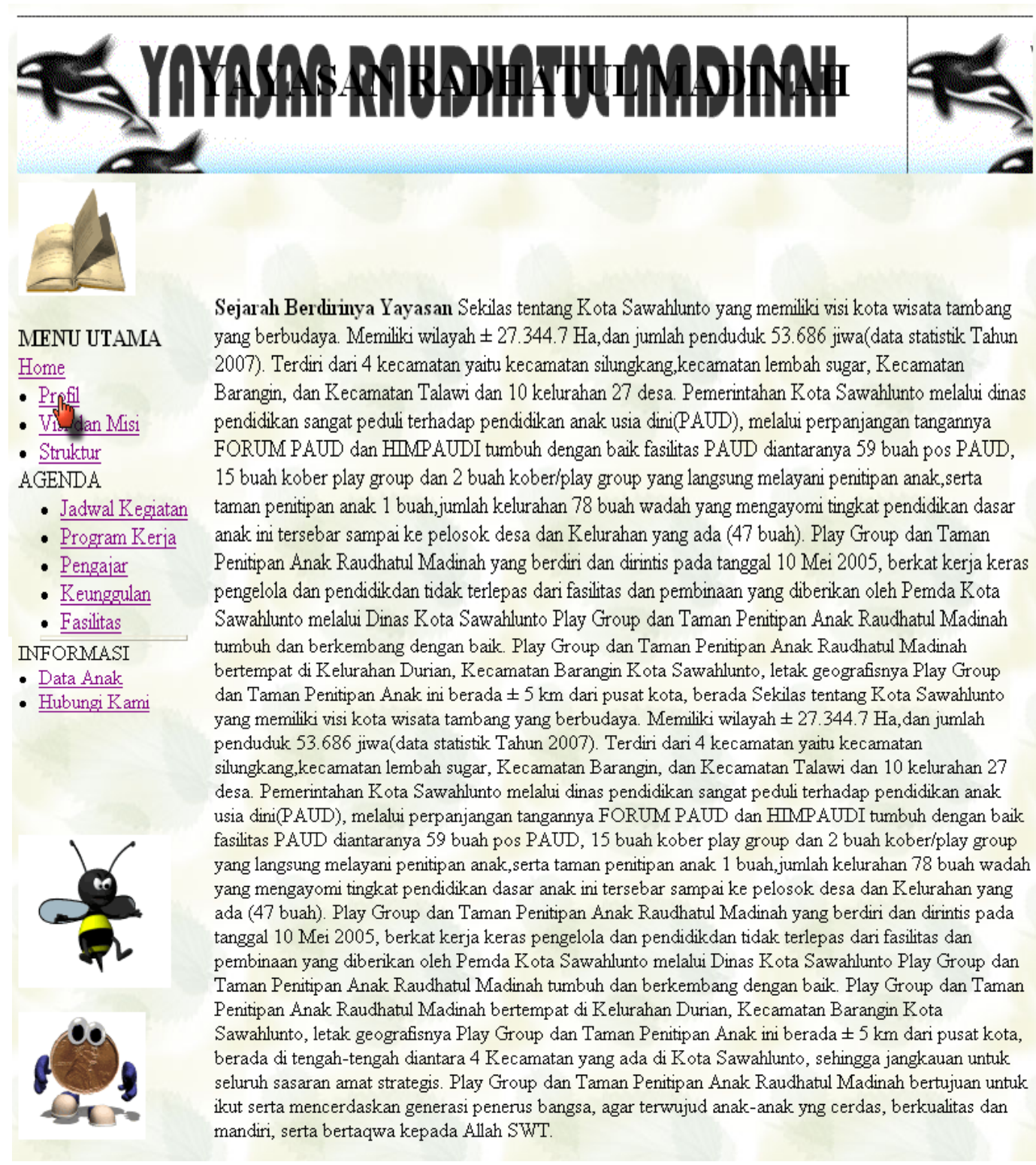

\section{Gambar Halaman Web Profil}

Form ini menjelaskan dan menerangkan bagaimana yayasan ini awl nya berdiri dan menjelaskan. Didalam profil ini kita dapat melihat bagaimana yayasan ini dikembangkan dan dijalankan apa sesuai dengan tujuan awalnya

\section{Halaman Web Kegiatan}




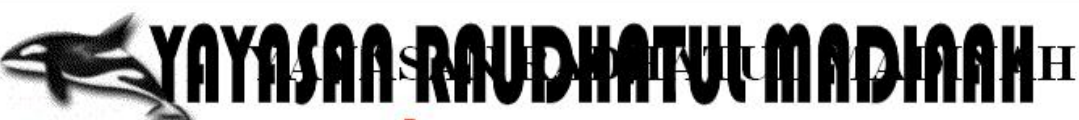

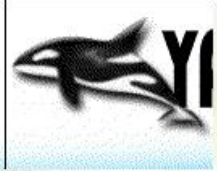

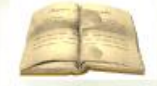

MENU UTAMA

Home

- Profil

- Visi dan Misi

- Struktur

AGENDA

- Jadwal Kegiatan

- Program Keria

- Pengajar

- Keunggulan

- Fasilitas

INFORMASI

- Data Anak

- Hubungi Kami

\begin{tabular}{|c|c|c|}
\hline Jadwal & Kegiatan & Penanggung Jawab \\
\hline Senin & $\begin{array}{l}\text { 1-2 Tahun } \\
\text { Bermain Balok(10 menit) }\end{array}$ & $\begin{array}{l}\text { Bu Neni dan Mama } \\
\text { Adeq }\end{array}$ \\
\hline Senin & $\begin{array}{l}\text { 3-5 Tahun } \\
\text { Mengenal Anggota tubuh dalam } \\
\text { bahasa inggris }\end{array}$ & Mama Nur \\
\hline Selasa & $\begin{array}{l}\text { 1-2 Tahun } \\
\text { Bermain dan Mengenal nama } \\
\text { binatang }\end{array}$ & $\begin{array}{l}\text { Bu Dona dan Mama } \\
\text { Adek }\end{array}$ \\
\hline Rabu & $\begin{array}{l}\text { Olah Raga(Semua Anak) } \\
\text { Berenang }\end{array}$ & Semua Guru \\
\hline Kamis & $\begin{array}{l}\text { 1-2 Tahun } \\
\text { Bermain Peran }\end{array}$ & $\begin{array}{l}\text { Bu Neni dan Mama } \\
\text { Nur }\end{array}$ \\
\hline Jumat & Menggulang Pelajaran & Semua Guru \\
\hline
\end{tabular}

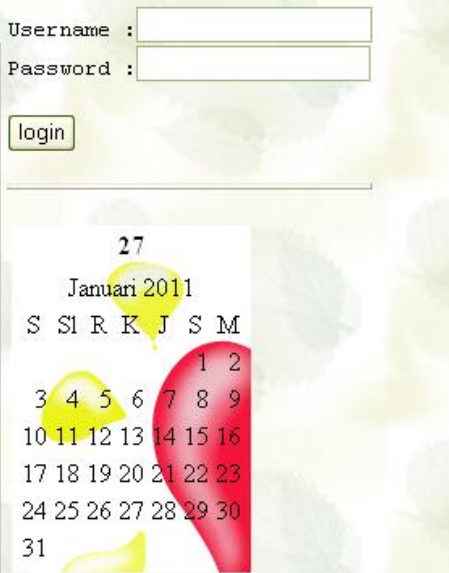

Gambar Halaman Web Kegiatan

Form ini menjelaskan tentang kegiatan anak didik setiap hari nya,adpun jadwal nya dapat dilihat seperti gambar

Halaman Web Program Kerja

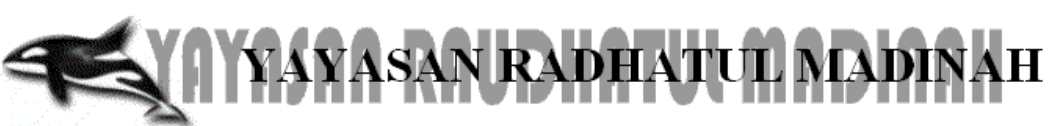

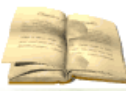

MENU UTAMA

Home

- Profil

- Visi dan Misi

- Struktur

- Jadwal Kegiatan

- Program Kerja

- Pengajar

- Keunggulan

- Fasilitas

INFORMASI

- Data Anak

- $\underline{\text { Hubungi Kami }}$
PROGRAM KERJA PLAY GROUP DAN TAMAN PENITIPAN ANAK

RAUDHATUL MADINAH

1.PROGRAM KERJA KE DALAM INTERN (KEDALAM)

Dalam melaksanakan proses bermain dan belajar anak didik, terus diberikan permainan yang berinovasi, dan juga melestarikan dan mengembangkan permainan dan tari tradisional.

Dalam pemantaun tumbuh kembang anak dilaksanakan penimbangan berat dan tinggi badan anak $1 \mathrm{x}$ se bulan, kunjungan dokter umum 1x3bulan, selanjutnya 3 bulan yang mendatang akan dikunjungi oleh dokter gigi 2.PROGRAM KERJA EKSTERN 9(KELUAR)

Menjadi PAUD unggulan untuk Tk. Kota Sawahlunto, memang sesuatu yang sangat diinginkan dimana Play Group dan Taman Penitipan Anak Raudhatul Madinah akan memberikan bantuan moril dan materil untuk anak yangorang tuanya krang mampu. 


\section{Gambar Halaman Web Program Kerja}

Program kerja Yayasan Raudhatul madinah terbagi 2 yaitu intern dan ekstern.dimana masing-masing nya mempunyai tujuan dalam mengembangkan mutu Yayasan Raudhatul Madinah

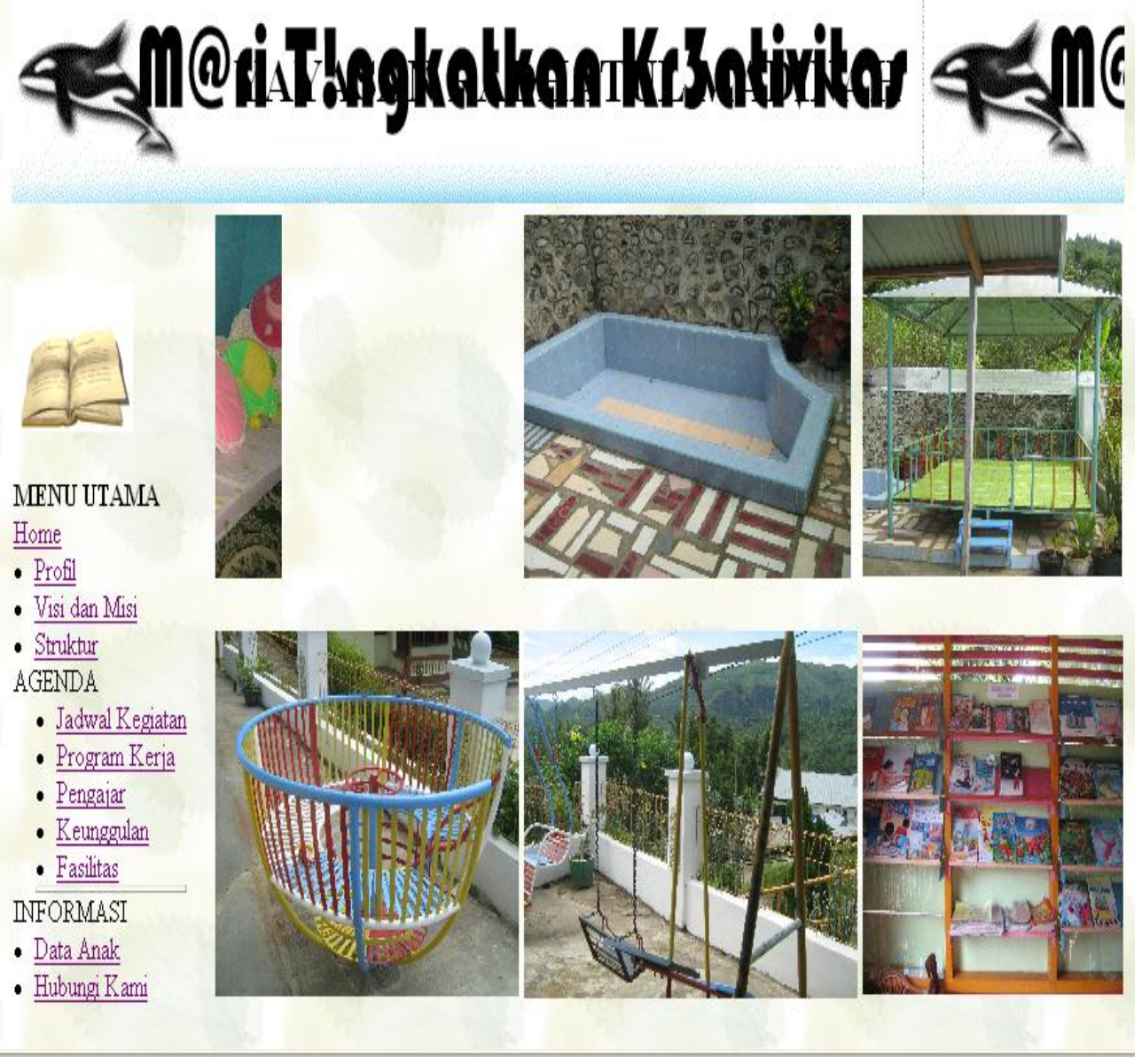

Gambar Halaman Web Fasilitas 
Form ini memperlihatkan fasilitas apa saja yang ada di yayasan raudhatul madinah mulai dari bermain sampai dengan belajar

\subsubsection{Halaman Web Data Anak}

\section{YAYASAN RADHATUL MADINAH}

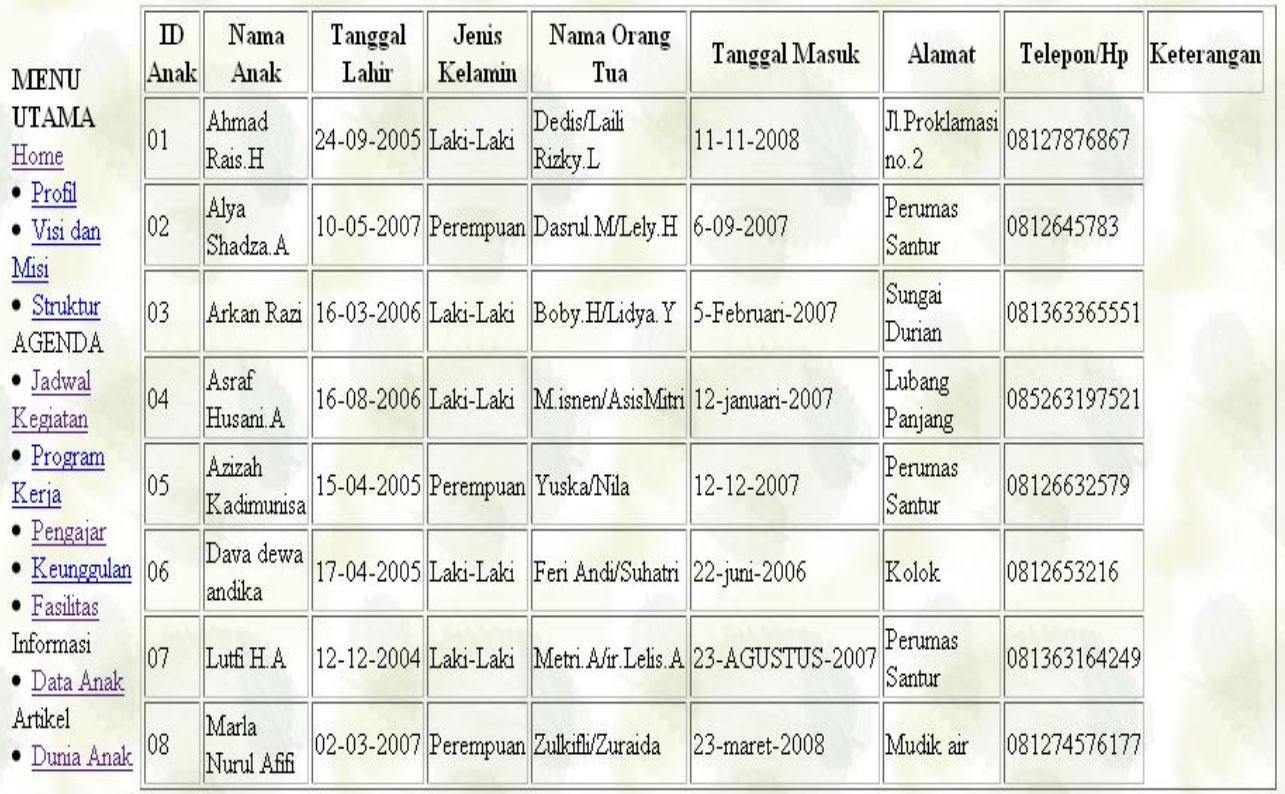

Gambar Halaman Web Data Anak

Form ini memperlihatkan data anak-anak yang di didik diYayasan Raudhatul Madinah seperti yang terlihat pada ganbar 4.12 Selama masi terdaftar sebagai anak asuh diYayasan tsb

\subsubsection{Form Login Admin}




\section{Username :}

Password :

\section{Gambar Form Login Admin}

\section{DAFTAR PUSTAKA}

Connoly T. M, et all. (1995). Database System-A Practical Approach to Design, Implementation and Management. Addison-Wesley

Eko Indrajit, Richardus.2001. Manajemen Sistem Informasi dan Teknologi Informasi. Jakarta:PT. Gramedia

Eksa. 2008. Buat Laporan dengan PHP. http://eksa.wordpress.com/2008/08/27/buatlaporan-dengan-php/feed/ (10 November 2009)

Fathansyah. Basis Data. Informatika. Bandung. 2001

Hakim, Lukmanul. 2008. Membongkar Trik Rahasia Para Master PHP. Yogyakarta: Lokomedia

Hariyanto, Bambang. Sistem Operasi, Ed. II. Informatika. Bandung. 2001

Hartono, Jogiyanto. Pengenalan Komputer ; dasar ilmu komputer, pemrograman, sistem informasi dan inteligensi buatan, Ed. III. Andi Offset.

Yogyakarta. 2002

Jack, Febian.Pengetahuan Komputer Dan Teknologi Informasi. Informatika. Bandung.2004

Jogiyanto HM. Analisa \& disain : Sistem informasi pendekatan terstruktur teori dan praktek aplikasi bisnis. Andi Offset. Yogyakarta. 2001 
Kadir, Abdul.2003. Pengenalan Sistam Informasi. Yogyakarta: Andi

Nugroho, Adi,. Analisis dan Perancangan Sistem Informasi dengan Metodologi Berorientasi Objek. Informatika. Bandung. 2002

Prasetyo, Didik Dwi. Administrasi database MySQL. PT. Elex Media Komputindo. Jakarta. 2003

Sidik, Bertha. (2003). MySQL. Informatika Bandung.

Simarmata, Janner. Aplikasi Mobile Commerce Menggunakan PHP Dan MySQL. Andi Offset.Yogyakarta.2006

Sopiandi, Dede. Instalasi dan konfigurasi jaringan komputer. Informatika Bandung. 2004

URL: http://www.ilmuwebsite.com (16 Desember 2009)

Widigdo, Anon. (2003). Dasar Pemrograman PHP dan MySQL. Ditemukan tanggal 14 Oktober 2006. Dari http://www.ilmukomputer.org 